Asian Review of Social Sciences ISSN: 2249-6319 Vol.7 No.1, 2018, pp. 21-25

(C) The Research Publication, www.trp.org.in

\title{
Proposed Theoretical Measurement Model for Financial Inclusion with Perspective of Refuge Inhabitants
}

\author{
S.Sheik Abdullah ${ }^{1}$, A.Krishna Kumar ${ }^{2}$ and B.Sheeba Pearline ${ }^{3}$ \\ ${ }_{1,2 \& 3}$ Assistant Professor, Department of Commerce, \\ P.M.T.College, Mellanellithanallur, Tamil Nadu, India \\ E-Mail: abdullah.sheik0499@gmail.com,Sheebarajan2005@gmail.com
}

\begin{abstract}
Financial inclusion takes into account the participation of vulnerable groups such as weaker sections of the society and low income groups, based on the extent of their access to financial services such as savings and payment account, credit insurance, pensions etc. Also the objective of financial inclusion exercise is easy availability of financial services which allows maximum investment in business opportunities, education, save for retirement, insurance against risks by the rural individuals and firms. The penetration of financial services in the rural areas of India is still very low. The factors responsible for this condition can be looked at from both supply side and demand side and the major reason for low penetration of financial services is, probably, lack of supply. The reasons for low demand for financial services could be low income level, lack of financial literacy, other bank accounts in the family, etc. On the other hand, the supply side factors include no bank branch in the vicinity, lack of suitable products meeting the needs of the poor people, complex processes and language barriers. There is no studies conducted earlier especially financial inclusion initiatives with refugee inhabitants. Therefore this study was undertaken to propose the model of refugee inhabitants towards financial inclusion initiatives by the banks. The exhibited model consisting four essential factors, which are very useful for measuring financial inclusion practices.
\end{abstract}

Keywords: Financial Inclusion, Refuge Inhabitants, Theoretical Model, EFA, CFA

\section{INTRODUCTION}

According to Mahatama Gandhi who stated, "Poverty is the worst form of violence" in order to avoid the poverty the government should promote inclusive development in economic aspects. For any country's economic parameter to progress subsequently thus demands an efficient financial system. The way in which financial system is accelerates in the form of financial inclusion. On the other hand financial inclusions are essential enabler for inclusive growth as well as include the financially excluded segments of the society. The wave of financial inclusion initiates many developing countries de-regulate and stimulate the public to progressive opening up and accessing the financial institution as well as financial maket. Financial services or products provided by banks, finance companies, postal savings banks, credit unions, insurance companies and micro finance institutions and other formal financial institutions generally form the base for financial inclusion. The financial services rendered by the informal institution do not come under the purview of financial inclusion. Nevertheless the banking institution in the roof of financial market plays important role in developing the economy. The developing economy like India, financial inclusion as the process of ensuring timely access to financial services and offer adequate credit to vulnerable groups at an affordable cost claimed by Rangaraj committee (2008). In another way the financial inclusion consists of ensuring bank accounts to each household. Thus, financial inclusion enables improved and better sustainable economic and social development of the country. It helps in the empowerment of the underprivileged, poor and women of the society with the mission of making them selfsufficient and well informed to take better financial decisions.

Financial inclusion is revamping account the participation of vulnerable groups such as weaker sections of the society and low income groups, based on the extent of their access to financial services such as savings and payment account, credit insurance, pensions and so on. Also the objective of financial inclusion exercise is easy availability of financial services which allows maximum investment in business opportunities, education, save for retirement, insurance against risks by the rural individuals and firms.

The penetration of financial services in the rural areas of India is still very low. The factors responsible for this condition can be looked at from both supply side and demand side and the major reason for low penetration of financial services is, probably, lack of supply. The reasons for low demand for financial services could be low income level, lack of financial literacy, other bank accounts in the family, etc. On the other hand, the supply side factors include no bank branch in the vicinity, lack of suitable products meeting the needs of the poor people, complex processes and language barriers.

The access of financial services promotes self-confidence and empowerment among the users. The Reserve Bank of India (RBI) and the Government of India (GOI) have been making efforts to increase financial inclusion. Measures such as SHG-bank linkage program, use of business facilitators and correspondents, easing of Know Your Customer (KYC) norms, electronic benefit transfer, separate plan for urban financial inclusion, use of mobile technology, 
bank branches and ATMs, opening and encouraging 'nofrill-accounts' and emphasis on financial literacy have played a significant role for inclusive development. The government had launched the high profile financial inclusion programme like Pradhan Mantri Jan Dhan Yojana (PMJDY) aimed at ensuring that all households have a bank account. The Yojana had resulted in opening of 125 million new bank accounts. Under the scheme more than 97 per cent of the accounts were opened with public sector banks. The report of WTO also noted that dormancy rate in India is quite high at 43 per cent and accounts for about 195 million of 460 million adults with a dormant account around the world (The Hindu Dated on $16^{\text {th }}$ April, 2015).

In sharp connotation, this is not good to the developing economy. Thus make the attention among the academician and researcher to pay off solution for this. But ease in accessing the financial data, there were sufficient studies were conducted in bank penetration and/or effect of literacy and financial inclusion in India. But there is no studies conducted earlier especially financial inclusion initiatives with refugee inhabitants. Therefore this study was undertaken to propose the theoretical model for financial inclusion with perspective of refugee inhabitants.

\section{STUDY CONUNDRUM}

In the last ten years, financial exclusion has emerged as a policy concern and funding has been made available at both national and local levels. There are many different initiatives under the auspices of Indian government departments and statutory bodies. In addition there is divergence between the policies and in the devolved administrations. The voluntary and private sectors also play a crucial role in providing services to financially excluded groups. Although banking sector in India has adopt world class initiation for including the societies from financially excluded.

Financial inclusion has two elements: good financial decision-making (the 'demand side' of the equation) and access to suitable products and services (the 'supply side'). According to UK report (2008), Those particularly vulnerable to financial exclusion include: housing association tenants; young people not in employment, education or training; those leaving care; lone parents and divorced people; disabled people, those with mental health problems and carers, people living in isolated or disadvantaged areas, prisoners, ex-offenders and families of prisoners, members of ethnic minorities, migrants, asylum seekers and refugees, homeless people, older people, women, people with a Post Office Card Account or basic bank account and people with low incomes. Over the past two decades, the world has been witnessing the largest and most diverse migration ever recorded in history. According to the UNHCR (2016), an unprecedented 65.6 million people around the world have been forced from home. Among them are nearly 22.5 million refugees, over half of whom are under the age of 18. A refugee is someone who has fled his or her country and cannot return because of a well-founded fear of persecution for reasons of race, religion, nationality, political opinion or membership in a particular social group. Refugees may also flee their countries due to serious and indiscriminate threats to life, physical integrity or freedom resulting from generalized violence or events seriously disturbing public order. Refugees also not exist from the financially excluded community. In order to equip the refugees in financially literate and make them to access of financial product deepen a special financial initiatives programme.

\section{A. Research Questions}

Based on the combined above said study problem further the following research questions more precisely chosen the topic for the research.

1. To identify whether refugee groups appear likely to remain financially excluded in the future?

2. To identify the strengths and weakness of current financial inclusion initiatives towards the Refugees'?

3. How bank and its financial inclusion practices address the needs of the refugee inhabitants?

4. Change of financial Policy and recommendation will affect the growth of Refugees in Tamil Nadu?

\section{REVIEW OF LITERATURE}

There were no studies conducted earlier with the perception of refugees towards financial inclusion in national and international level. The researcher will collect the comprehensively related literature in "Financial Inclusion" and this will help to form the hypothetical measurement model for financial inclusion in different constituent factor.

Carbo et al., (2007) find that the denial of financial services and the conditions that lead to depriving an individual or a group from the benefits of these services is called Financial Exclusion. It can be of any type like access - exclusion, condition - exclusion, price - exclusion, marketing exclusion or self - exclusion. It also depicts social deprivation or social standing. It can be due to many social and economic factors, viz: low household incomes, expensive source of credit, no savings and no insurance coverage. This takes us to the issue of 'Financial Inclusion'.

Chakraborthy, K.C. (2009) comments that Inclusive Growth cannot come without FI and enabling people to get credit from small money lenders and the like is not FI but the access has to be through mainstream institutional players and only then such access will be fair, transparent and cost effective sector. Banking system/institutions has a vital role in facilitating the development of financial system.

Sameer Kochaar (2009) remarks that to address the issue of Financial Exclusion in a holistic manner, it is essential to ensure that the following financial services are available to every individual. (i) A no - frill banking account for making and receiving payments, (ii) A savings product suited to the 
pattern of cash flow of a poor household, (iii) Money transfer facilities,(iv) Small loans and overdrafts for productive, personal and other purposes, (v) Micro insurance, and (vi) Micro - pensions.

Nageswara Rao (2010) observes that the objective before present day economy is to ensure growth with distributive justice in tune with the democratic principles of the greatest happiness to the greatest number. Growth cannot be considered as an end itself until it translates into income generation and empowerment of the whole population irrespective of areas and sectors.Growth has to be an inclusive phenomenon and not confined to a few pockets of area and people which makes it exclusive.

Subha, Rao (2010) stated that the statistics do not convey the true extent of Financial Exclusion. Even where bank accounts are claimed to have been opened, verification has shown that these accounts are dormant. Few conduct any banking transactions and even fewer receive any credit. Millions of people across the country are thereby denied the opportunity to harness their earning capacity and entrepreneurial talent and are condemned to marginalization and poverty.

\section{OBJECTIVES OF THE STUDY}

The main objective of the study is to identify the importance of financial inclusion and its initiation towards refugee inhabitants and also the following objectives have been identified by the researcher. The main objective of this study is to form the theoretical model of financial inclusion, the secondary objectives are.

1. To understand the specific needs of the target group in terms of where, when and how to deliver financial assistance.

2. To analyse the refugees level of literacy towards banking products.

3. To measure the financial inclusion initiatives in different constituent factors.

4. To form the hypothetical measurement model for financial inclusion especially for refugees.

5. To offer suitable suggestion and recommendation for retaining refugees from financially excluded

\section{A. Hypotheses of the study}

Based on the above objectives the following null hypothesis has been framed by the researcher.

1. Access, quality, usage and welfare factor does not influence financial inclusion.

2. Financial inclusion perception not positively associate with refugee inhabitants' satisfaction towards banking products.
3. Financial literacy practices don’t make the refugees to frequent uses of financial products.

\section{B. Theoretical measurement model for measuring financial inclusion}

Financial and inclusion by itself is a multi-faceted concept with a number of nuanced components, all or some of which may be relevant to the specific country agenda. The following of four commonly used lenses through which financial inclusion can be defined, in order of complexity:

ACCESS - This component is concerned primarily with the ability to use available financial services and products from formal institutions. Understanding levels of access may therefore require insight and analysis of potential barriers to opening and using a bank account for any purpose, such as cost and physical proximity of bank service points (branches, ATMs, etc).A very basic proxy for access can be derived through counting the number of open accounts across financial institutions and estimating the proportion of the population with an account. Data on access can usually be obtained through information provided by financial institutions.

QUALITY - As a measure of the relevance of the financial service or product to the lifestyle needs of the consumer, quality encompasses the experience of the consumer, demonstrated in attitudes and opinions towards those products that are currently available to them. The measure of quality would therefore be used to gauge the nature and depth of the relationship between the financial service provider and the consumer as well as the choices available and their levels of understanding of those choices and their implications.

USAGE - Concerned with more than basic adoption of banking services, usage focuses more on the permanence and depth of financial service / product use. In other words, determining usage requires more details about the regularity, frequency and duration of use over time. Usage also involves measuring what combination of financial products is used by any one person or household.

WELFARE - The most difficult outcome to measure is the impact that a financial device or service has had on the lives of consumers, including changes in consumption, business activity and wellness. In order to acquire information on quality, usage and welfare, it is critical to have information from the user's point of view, i.e. data gathered through a demand-side survey. The following figure shows the measurement model of financial inclusion. Based on the four components the researcher form the model and develop the measurement scale to measure the financial inclusion. 


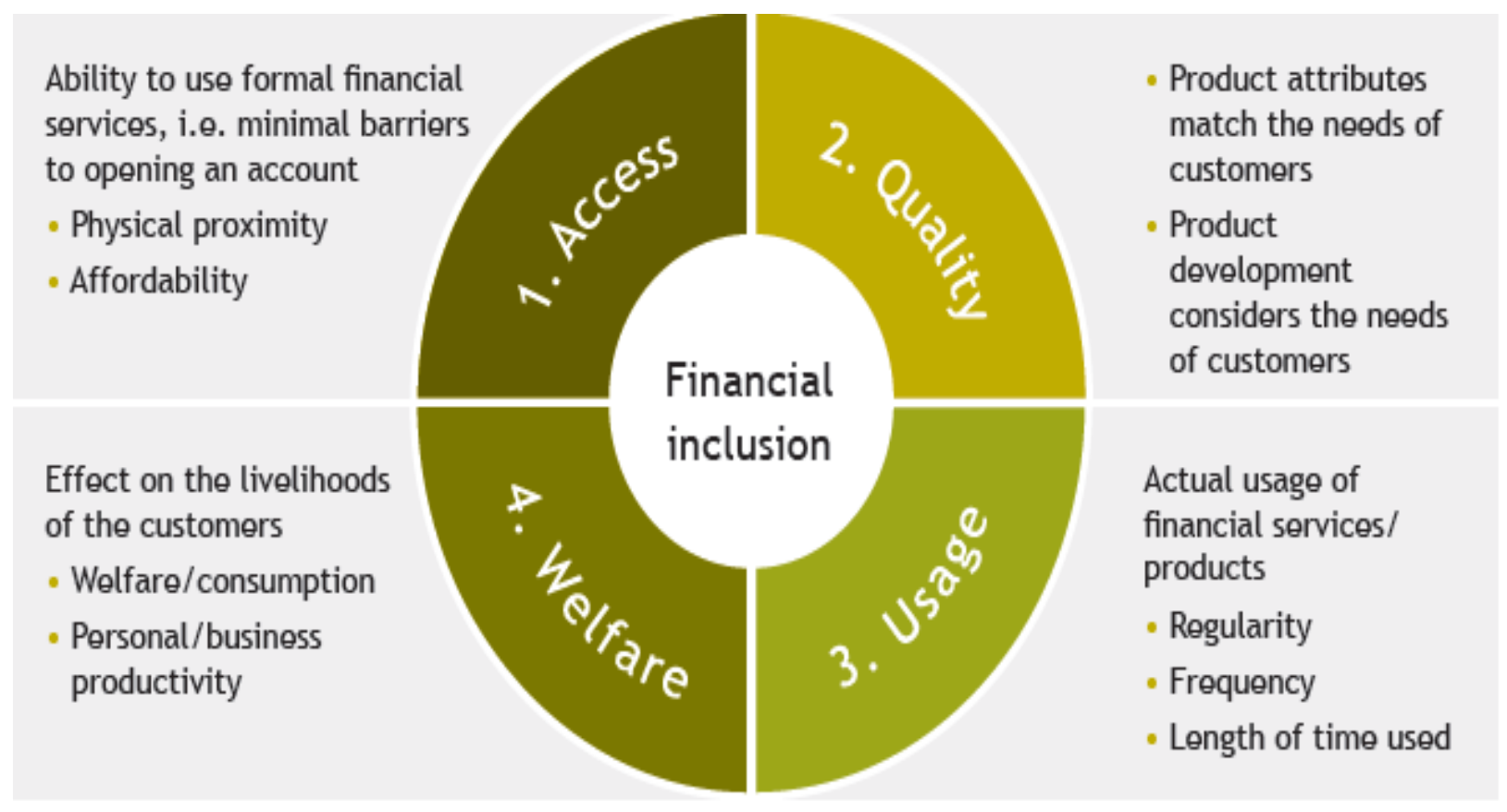

Fig. 1 Financial Inclusion Measurement for Regulators, Alliance Financial Inclusion

\section{V.STATISTICAL TOOLS}

For analyzing the data collected during the investigation, the following statistical tools were used based upon the nature of data and relevance of the information required.

\section{A. Exploratory Factor Analysis (EFA)}

Exploratory Factor analysis is a general name denoting a class of procedures primarily used for data reduction on summarization. In marketing research, there may be a large number of variables, most of which are correlated and which must be reduced to manageable level. Relationship among sets of many interrelated variables are examined and represented in terms of a few underlying factors.

\section{B. Confirmatory Factor Analysis (CFA)}

The confirmatory factor analysis is a statistical tool which is used to test the reliability and validity of the variables included in each factor identified by the EFA. The important statistics drawn from the CFA are the standardized factor loading of the variables, its t statistics, composite reliability and average variance. These are computed for the purpose of testing the content, convergent, and discriminant validity of the factor extracted by the EFA.

In the present study, the CFA is applied to test the reliability and validity of variables included in each factor extracted by the EFA.

\section{RESEARCH METHODOLOGY}

The present study is based on both primary as well as secondary data. The primary data are those data, which are collected from the respondents in refugee camp in Tamilnadu. For that, a separate pre tested schedule was constructed and collected to bring out opinion of the respondents about the initiation of financial inclusion by the banks.

The secondary data are those data, which are already collected by someone else. The researcher has collected the secondary data from the records of commercial banks, journals such as Indian Journal of Marketing, Indian Banks Associations Bulletin (IBAB), banking studies and so on.

\section{A. Panel Interview}

The face and content validity of the instrument is evaluated with the panel of experts. The panel consists of two teaching faculty, who are well versed in finance and marketing, researcher and two externals from banking institution. The panel members are asked to offer recommendation about the scale items adopted for the study from past literature. After availing panel members opinion the researcher has make appropriate changes in the scale item in the latent construct which is measuring the financial inclusion practices. After the panel recommendation, the data collection instrument reliability and validity measured through pre-test. The pretest will be conducted with 40 respondents. Suppose the internal consistency of the scale measurement Alpha value is found as above 0.07 , this will indicates a good internal consistency of scale item used for this study. 


\section{SAMPLING DESIGN}

As per the available records of tamilnadu rehabilitation department, 1,01,219 refugees were migrated in the state. Due to geographical region most refugees are from the country of Srilanka. Through the government assistance around 63,351 refugees residing in 107 regular camps and in one special camps situated in 24 districts of Tamilnadu. It's very difficult to the researcher to collect the data from whole refugees in Tamilnadu. Therefore the researcher will decide to collect the data from the refugee camp located in south part of Tamilnadu.

The southern part of Tamilnadu consists Madurai, Ramanathapuram, Virudhunagar, Tirunelveli, Thoothukudi and Kanyakumari and all these districts have refugee camps. In six district 26 refugee camps with refugee population of 16,818 persons resided. It's not feasible to adopt census study; in order to identify the appropriate sample size the researcher uses the sample size calculator application to identify the sample.

According to sample size calculator 640 (5\% confidence and $5 \%$ interval level) sample is appropriate for this study. After identifying the sample size, the respondents are selected on the basis of random sampling method. The extensive sample selection demonstrated in the following Table 1.

TABLE 1 CAMP POPUlation District WiSE In TAMILNADU (As ON $1^{\text {ST }}$ NOVEMBER,2016)

\begin{tabular}{|l|c|c|c|c|c|}
\hline \multicolumn{1}{|c|}{ District } & No. of Camps & No. of Families & $\begin{array}{c}\text { Total No.of } \\
\text { population }\end{array}$ & $\begin{array}{c}\text { Percentage } \\
\text { to total* }\end{array}$ & $\begin{array}{c}\text { Allocation of sample } \\
\text { to each district** }\end{array}$ \\
\hline Madurai & 3 & 1695 & 5833 & 35 & 224 \\
\hline Virudhunagar & 7 & 974 & 3398 & 20 & 128 \\
\hline Ramanathapuram & 1 & 584 & 1914 & 11 & 71 \\
\hline Tirunelveli & 8 & 861 & 2669 & 16 & 102 \\
\hline Thoothukudi & 3 & 467 & 1629 & 10 & 64 \\
\hline Kanyakumari & 4 & 432 & 1375 & 8 & 51 \\
\hline \multicolumn{1}{|c|}{ Total } & 26 & 5013 & 16818 & 100 & 640 \\
\hline
\end{tabular}

* Calculated weights to total population ** sample allotted on the basis weights

\section{CONCLUSION}

This study will undertake to analyse the perception of refugee inhabitants towards financial inclusion, during the time of discussion with target audience there is no special initiation taken by the banks in respect of financial inclusion. Financial inclusion concept is collectively enforced the community to participate and insisting to use of financial products. Although the refugee inhabitants are hesitated to use these products, they get limited benefit from the financial institution. The light finding is not taken for monitoring recommendation. The reason is beyond the scope of this research. In order to anticipate the problem, the in-depth study is needed. Only after conducting the depth study the researcher will come to conclude. The present work is proposing the theoretical model which will used by the researcher for empirical investigation in upcoming research.

\section{REFERENCES}

[1] Agarwal and Parul, "Financial Inclusion in India: a Review and Initiatives and Achievements", IOSR Journal of Business and Management, Vol. 16, June 2014.

[2] Carbo, S. Gardener, Edward, Philip, P.M. and Molyneux, Financial Exclusion, Palgrave Macmillan, 2007.

[3] K. C. Chakraborthy, Introductory Notes in Sameer Kochaar (Ed.) Speeding Financial Inclusion, New Delhi, Academic foundation, pp. 19-23, 2009.
[4] R. G. Clarke, Geroge, L. Colin Xu, and Heng-fu Zou. "Finance and Inequality: What Do the Data Tell Us?", Southern Economic Journal Vol. 72, No. 3, pp. 578-96, 2006.

[5] K. Divya, "A Study On Impact Of Financial Inclusion With Reference To Daily Wage Earners”, Journal of Business Management \& Social Sciences Research, Vol. 2, June 2014.

[6] Gupta and Sanjeev Kumar, "Financial Inclusion - IT as an enabler", RBI Occasional Paper, Vol. 32, No. 2, 2011.

[7] M. Gomathy, "An Overview of Financial Inclusion and rural development in India", IOSR Journal of Business and Management, Vol. 17, pp. 06-11, Aug. 2015.

[8] Government of India, "Committee on Financial Inclusion" (Chairman: Dr. C. Rangarajan), 2008.

[9] Michael Chibba, "Financial Inclusion, Poverty Reduction and the millennium Development Goals”, European Journal of Development Research, Vol. 21, April 2009.

[10]N. Rao, "Financial Inclusion-Banker's Perspective", The Journal of Indian Institute of Banking \& Finance (Bank Quest), Vol. 81, No. 4, pp. 20-26, October-December 2010.

[11]R. Srikanth, "A Study on - Financial Inclusion - Role of Indian Banks in Reaching Out to the Unbanked and Backward Areas", International Journal of Applied Research and Studies, Vol. 2, Sept. 2013.

[12]Sameer Kochaar, Speeding Financial Inclusion, New Delhi, Academic foundation, 2009. 